Acta Cryst. (1977). B33, 946-948

\title{
Radioprotectant Sodium Fluoroacetate
}

\author{
By B. M. Vedavathi and Kalyani ViJayan \\ Materials Science Division, National Aeronautical Laboratory, Bangalore-560017, India
}

(Received 14 September 1976; accepted 1 December 1976)

\begin{abstract}
FCH}_{2} . \mathrm{COO}\right)^{-} . \mathrm{Na}^{+} ; P 2_{1} ; a=9 \cdot 32(1), b=$ $5.33(1), c=3.65(2) \AA, \beta=99.4(5)^{\circ} ; D_{m}=1.79$ (flotation); $D_{c}=1.86 \mathrm{~g} \mathrm{~cm}^{-3} ; Z=2$. The $\mathrm{Na}^{+}$ion is coordinated by five $\mathrm{O}$ atoms and a $\mathrm{F}$ atom which form a distorted octahedron. The average value of the $\mathrm{Na}$... O distances in the octahedron is $2.46(2) \AA$ and the $\mathrm{Na} \cdots \mathrm{F}$ distance is 2.56 (2) $\AA$. By including also a long $\mathrm{Na} \cdots \mathrm{O}$ distance of $2.98(2) \AA$ in the $\mathrm{Na}$ coordination, the polyhedron becomes seven-cornered with the $\mathrm{F}$ atom centring a face of the distorted trigonal prism formed by the $\mathrm{O}$ atoms. In the fluoroacetate ion, the $\mathrm{F}$ atom is cis to one of the carboxylate $\mathrm{O}$ atoms.
\end{abstract}

Introduction. A very tiny, transparent crystal of sodium fluoroacetate, about $0.2 \times 0.2 \times 0.3 \mathrm{~mm}$, was obtained by slow evaporation from aqueous solution. Efforts to obtain larger crystals by the same and different procedures were not fruitful. Hence, the one tiny crystal was used for data collection. Intensity data from reciprocal levels $h k l, l=0$ to 2 , were recorded on multiple films by the equi-inclination Weissenberg method with $\mathrm{Cu} K \alpha$ radiation. The diffraction pattern was generally weak. When the second-level data were recorded, the spot shape of the reflexions was beginning to change, indicating deterioration of the sample, and soon after the recording of that level, the specimen lost its crystallinity and acquired a chalky appearance. The intensities of 207 observed reflexions were measured by comparison with a calibrated strip and were corrected for Lp and spot-shape effects.

The structure was solved by direct methods followed by Fourier methods. MULTAN (Germain, Main \& Woolfson, 1971), as modified by S. Ramakumar and N. Murthy for the IBM 360/44 computer, was used with $84 E$ 's greater than $1 \cdot 0$. From the $E$ map corresponding to the best solution of MULTAN, the positions of the $\mathrm{Na}^{+}$ion and the two acetate $\mathrm{O}$ atoms could be obtained. From a subsequent difference electron density map, the positions of the rest of the atoms in the structure were derived. The structure was refined by an iterative, block-diagonal structure-factor least-squares procedure. Anisotropic thermal parameters were employed and Cruickshank's weighting scheme with the constants $a=2.95, b=0.53$ and $c=$ 0.030 was used. When the least-squares refinement converged, $R$, defined as $\Sigma|| F_{o}|-| F_{c}|| \Sigma\left|F_{o}\right|$, for 207 observed reflexions was $0 \cdot 127$. The least-squares program used was originally written by $\mathrm{R}$. Shiono and later modified by B. S. Reddy. The scattering factors were those of Cromer \& Waber (1965).

Discussion. Sodium fluoroacetate is well known for its protective action against ionizing radiation (Bacq, Fischer \& Herve, 1958). This analysis forms part of a 

Table 1. Final atomic coordinates in fractional units $\left(\times 10^{3}\right)$ with e.s.d.'s in parentheses

\begin{tabular}{lcr} 
& $x$ & $y$ \\
$\mathrm{Na}$ & $115(1)$ & \multicolumn{1}{c}{599} \\
$\mathrm{O}(1)$ & $121(1)$ & $288(3)$ \\
$\mathrm{O}(2)$ & $186(2)$ & $-112(3)$ \\
$\mathrm{C}(1)$ & $206(2)$ & $103(5)$ \\
$\mathrm{C}(2)$ & $358(2)$ & $159(4)$ \\
$\mathrm{F}$ & $363(1)$ & $401(3)$
\end{tabular}

Table 2. Final bond lengths $(\AA)$ bond angles $\left(^{\circ}\right)$ and dihedral angles $\left({ }^{\circ}\right)$ in the fluoroacetate ion, with e.s.d.'s in parentheses

$\begin{array}{rrr}\mathrm{O}(1)-\mathrm{C}(1) & 1.27(3) & \mathrm{O}(1)-\mathrm{C}(1)-\mathrm{O}(2) \\ \mathrm{O}(2)-\mathrm{C}(1) & 1.22(3) & \mathrm{O}(1)-\mathrm{C}(1)-\mathrm{C}(2) \\ \mathrm{C}(1)-\mathrm{C}(2) & 1.54(3) & \mathrm{O}(2)-\mathrm{C}(1)-\mathrm{C}(2) \\ \mathrm{C}(2)-\mathrm{F} & 1.41(3) & \mathrm{C}(1)-\mathrm{C}(2)-\mathrm{F} \\ & \mathrm{O}(2)-\mathrm{C}(1)-\mathrm{C}(2)-\mathrm{F} & -172(2) \\ \mathrm{O}(1)-\mathrm{C}(1)-\mathrm{C}(2)-\mathrm{F} & 15(3)\end{array}$

programme of $\mathrm{X}$-ray structural investigations on radioprotectants (Vijayan, Mani, Vedavathi \& Ramaseshan, 1975; Vijayan \& Mani, 1977).

The final positional coordinates are given in Table 1, with the e.s.d.'s.* The interatomic distances and valency angles are presented in Table 2 . These values are comparable within experimental error $(\Delta<3 \sigma)$ to the molecular dimensions observed in the crystal structures of ammonium trifluoroacetate (Cruickshank, Jones \& Walker, 1964), Cs and K hydrogen di(trifluoroacetate) (Golič \& Speakman, 1965) and Ag trifluoroacetate (Griffin, Ellett, Mehring, Bullitt \& Waugh, 1972). The dihedral angles presented in Table 2 describe the conformation of the acetate ion. Even though the seemingly sterically favoured position for the $\mathrm{F}$ atom is one in which it is nearly equidistant from the $\mathrm{O}$ atoms, it is found to be cis with respect to the $\mathrm{O}$ atom $\mathrm{O}(1)$. A similar molecular conformation has been observed in the crystal structure of monofluoroacetic acid (Kanters \& Kroon, 1972). The $\mathrm{Na} \cdots \mathrm{O}$ and $\mathrm{Na} \ldots \mathrm{F}$ distances in the coordination polyhedron of the $\mathrm{Na}^{+}$ion are listed in Table 3. The $\mathrm{Na}^{+}$ion is surrounded by five $\mathrm{O}$ atoms and a $\mathrm{F}$ atom which together form a distorted octahedron. The $\mathrm{Na}$... O distances in the octahedron range from 2.35 (2) to 2.61 (2) $\AA$, the average value being 2.46 (2) $\AA$. In addition to these six atoms, there is another $\mathrm{O}$ atom situated 2.98(2) $\AA$ from the $\mathrm{Na}^{+}$ion. Similar long $\mathrm{Na} \cdots \mathrm{O}$ distances have been observed in the crystal structures of monosodium

* Lists of structure factors and anisotropic thermal parameters have been deposited with the British Library Lending Division as Supplementary Publication No. SUP 32332 (3 pp.). Copies may be obtained through The Executive Secretary, International Union of Crystallography, 13 White Friars, Chester CH1 1NZ, England.
Table 3. $\mathrm{Na} \cdots \mathrm{O}$ and $\mathrm{Na} \cdots \mathrm{F}$ distances $(\AA)$ in the coordination polyhedra

\begin{tabular}{|c|c|c|c|}
\hline $\mathrm{Na} \cdot \mathrm{O}\left(1^{\mathrm{i}}\right)$ & $2.43(2)$ & $\mathrm{Na} \cdot \mathrm{O}\left(1^{v}\right)$ & $2.41(2)$ \\
\hline $\mathrm{Na} \cdots \mathrm{O}\left(2^{\mathrm{ii}}\right)$ & $2 \cdot 61(2)$ & $\left.\mathrm{Na} \cdot \mathrm{O}_{\left(2^{v}\right.}\right)$ & $2.98(2)$ \\
\hline $\mathrm{Na} \cdots \mathrm{O}\left(1^{\mathrm{iii}}\right)$ & $2.50(2)$ & $\mathrm{Na} \cdots \mathrm{F}^{i}$ & $2 \cdot 56(2)$ \\
\hline
\end{tabular}

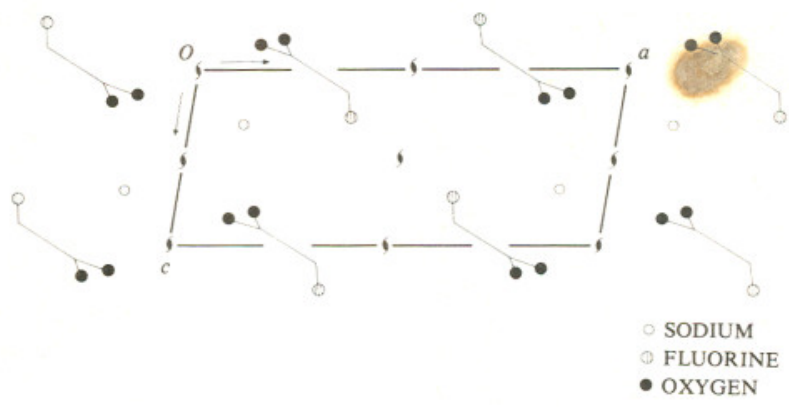

Fig. 1. A view of the crystal structure along the $[010]$ direction.

inosine-5'-monophosphate octahydrate (Rao \& Sundaralingam, 1968) and the hydrated disodium salt of adenosine triphosphate (Kennard et al., 1970), where the $\mathrm{O}$ atom is reported to coordinate to the $\mathrm{Na}^{+}$ion. In sodium fluoroacetate, the six $\mathrm{O}$ atoms surrounding the cation form a distorted trigonal prism. However, the coordination polyhedron formed by the six $\mathrm{O}$ atoms and the $\mathrm{F}$ atom is seven-cornered with the $\mathrm{F}$ atom centring a face of the trigonal prism.

A view of the structure as seen along the $[010]$ direction is given in Fig. 1. In the $a c$ plane, the fluoroacetate ion is so oriented that the $\mathrm{Na}^{+}$ion is sandwiched between two pairs of $\mathrm{O}$ atoms. The $\mathrm{Na}^{+}$ions related by the 2, screw axis and their respective coordination polyhedra repeat along $\mathbf{c}$ to form an infinite column. The forces between neighbouring columns are mainly of the non-bonded van der Waals type. Along $\mathbf{b}$, the $\mathrm{Na}^{+}$and fluoroacetate ions are arranged alternately and the $\mathrm{Na}^{+}$ ion is again sandwiched by two pairs of $\mathrm{O}$ atoms.

The authors wish to thank Dr S. Ramaseshan for his kind interest in the problem. One of us (BMV) thanks the Council of Scientific and Industrial Research, India, for the award of a junior research fellowship.

\section{References}

Bacq, Z. M., Fischer, P. \& Herve, A. (1958). Nature, Lond. 182, 175-176.

Cromer, D. T. \& Waber, J. T. (1965). Acta Cryst. 18, 104109.

Cruickshank, D. W. J., Jones, D. W. \& Walker, G. (1964). J. Chem. Soc. pp. 1303-1314. 
Germain, G., Main, P. \& Woolfson, M. M. (1971). Acta Cryst. A27, 368-376.

Golič, L. \& Speakman, J. C. (1965). J. Chem. Soc. pp. $2530-2542$.

Griffin, R. G., Ellett, J. D., Mehring, M., Bullitt, J. G. \& Waugh, J. S. (1972). J. Chem. Phys. 57, 2147-2155.

Kanters, J. A. \& Kroon, J. (1972). Acta Cryst. B28, 19461949.

Kennard, O., Isaccs, N. W., Coppola, J. C., Kirby, A. J.,
Warren, S., Motherwell, W. D. S., Watson, D. G., WAmpler, D. L., Chenery, D. H., Larson, A. C., KerR, K. A. \& Sanseverino, L. H. (1970). Nature, Lond. 225, 333-336.

Rao, S. T. \& Sundaralingam, M. (1968). Chem. Commun. pp. 995-1000.

ViJayan, K. \& Mani, A. (1977). Acta Cryst. B33, 279-280.

ViJAyAn, K., Mani, A., Vedavathi, B. M. \& Ramaseshan, S. (1975). Acta Cryst. A31, S58. 